\title{
The impact of occupational risks in the operating and maintenance activities in the energy sector
}

\author{
Georgiana Buica ${ }^{1, *}$, Anca Elena Antonov ${ }^{2}$, Constantin Beiu ${ }^{1}$, Dragos Pasculescu ${ }^{3}$, and \\ Remus Dobra ${ }^{4}$ \\ ${ }^{1}$ INCDPM „Alexandru Darabont”, Electrical and Mechanical Risks Laboratory, 35A Blvd, \\ Bucharest, Romania \\ 2, INCDPM „Alexandru Darabont”, Certification Body, 35A Blvd, Bucharest, Romania \\ ${ }^{3}$ University of Petrosani, Department of Control Engineering, Computers, Electrical Engineering and \\ Power Engineering, 20 Universitatii St., Petrosani, Romania \\ ${ }^{4} 1$ Decembrie 1918 University of Alba Iulia, Department of Computer Science and Engineering, 5 \\ Gabriel Bethlen St., Alba Iulia, Romania
}

\begin{abstract}
This paper presents a synthesis of studies in electrical installations from the energy sector, relating to occupational hazards, in terms of history of operations, maintenance, including situations that arose after some events that involved accidents at work and occupational diseases. Over the years, the energy sector has undergone a number of changes to the organizational level, modernization of electrical installations and implementations of new technologies and working procedures. As a result of these changes, has increased, over time, the level of safety of electrical installations, as well as the activities carried out by the operating and maintenance personnel that requires a high degree of training, as determined by the responsibilities assigned by job descriptions and procedures and as a result of physical and psychological stress to which the worker is subject during carrying out the activity. The research study aims to highlight the safety measures and health needed to be taken and their effectiveness to mitigate risks in the energy sector, in order to manage, more effectively, the work carried out by the operating and maintenance personnel of electrical installations, in order to ensure the healthy workplaces and to fulfil the occupational management objectives.
\end{abstract}

\section{Introduction}

Investigation on working conditions in the electricity distribution installations, for 19692015 and the assessment of risk level in electrical installations of production, transmission, distribution and use of electricity, together with technical and judicial expertise on accidents at work, led to analyse the solutions adopted by employers in order to fulfil the objectives of the management plan for quality of service, the level of safety in electrical installations, the safety provided for personnel, population and environment.

*Corresponding author: gbuica@protectiamuncii.ro 
The statistics on accidents at work at national level, processed in research studies indicate that there is a low decrease in number of accidents, according to records of National Statistics Institute (NSI) in the Production and supply of electricity, gas and water section, presented in Figure no.1 [1, 2].

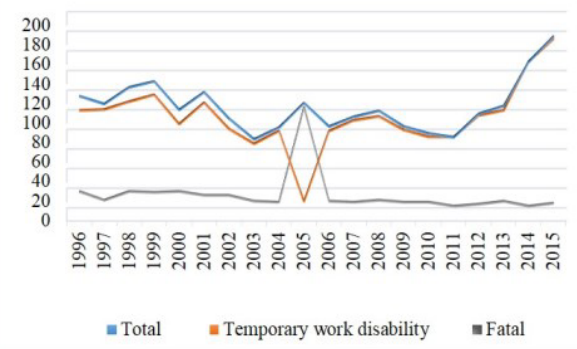

Fig. 1. Total work accidents produced in Romania, during 1996-2015

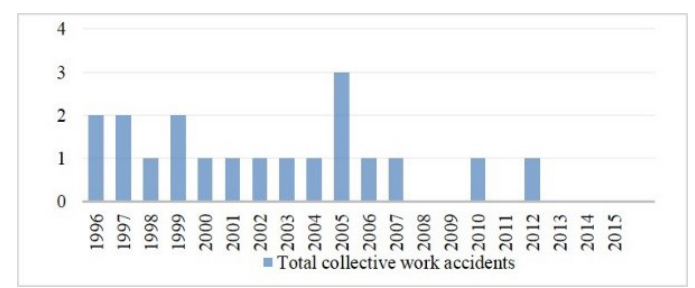

Fig. 2. Total collective accidents at work produced in Romania, during 1996-2015

The analysis allowed the identification of the increasing number of workers involved in work accidents and collective work accidents at is missing in the last three years.

\section{Summary of studies on the risks identified in operating - maintenance activities of electrical installations}

In order to diagnose the technical condition and safety of electrical installations, research studies consisted in identifying occupational risk factors related to the operating and maintenance of these installations, through the interaction of the four elements that constitute the work system.

In carrying out the operation and maintenance of electrical installations, the principle of division of work, by designating specific, well defined, of workers' participation and by establishing individual responsibility throughout whole activity, from the disposition of work, its organization, to execution and reception.

Analysing the technical, safety documents and job descriptions, it is noted that the work carried out by the personnel of operation and maintenance is a complex one and involves a high degree of training, accountability and require neuropsychological stress, e.g. due to the short time in which the work must be carried out, the need to take quick decisions that can have serious consequence, because of possible errors in carrying out the operations.

The electrical installations, depending on their field and category, have in composition the same types of electrical equipment, based on some standard operating diagrams, schemes that may have certain particularities, depending on the role in the electrical power system.

The degree of protection for the work equipment in electrical installations, confirms a good level of safety. It should be noted, however, that some of the equipment is in the last period of reliability, which can increase the probability of defects and, therefore, can decrease the safety level [3].

In recent years there has been a growing number of upgraded power stations leading to the elimination of these risks, and increasing the number of manoeuvres carried out by the operating personnel, during the upgrading activities. 


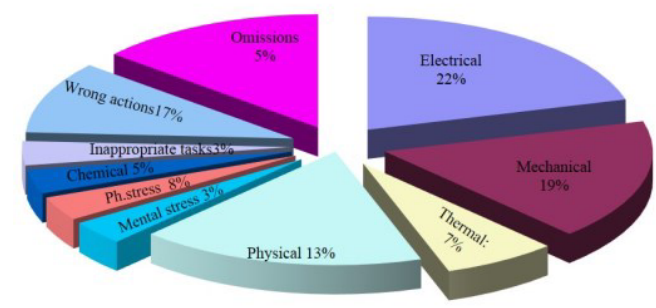

Fig. 3. Risk factors share identified in substations, on operations and maintenance activities

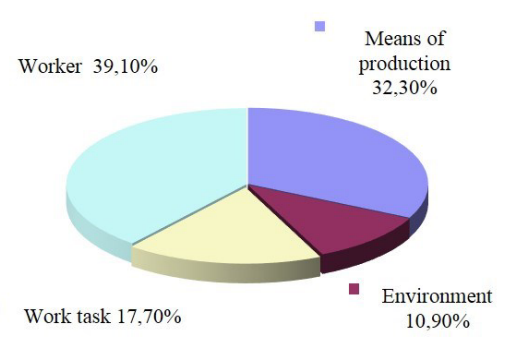

Fig. 4. The distribution of risk factors based on components of work components in substations, on operations and maintenance activities

The largest share of the risk factors identified in electric substations, from all the risk factors identified in the assessment process, are electrical risk factor, with $23 \%$ and $19 \%$ mechanical risk factors. Figure 3 presents the share risk factors identified in substations, on operations and maintenance activities.

In figure 2 is presented the risk factors share identified in the electrical installations for the overhead power lines, and found that mechanical risk factors and risk factors generated by the workers have the highest percentage $18 \%$. The electrical risk factors share identified are only $17 \%[5]$.

In recent years there has been a decrease in the weighting of electric risk factors, from $28 \%$ to $23 \%$, of the factors generated by inappropriate tasks, from $9 \%$ to $4 \%$, due to upgrades or modernization and introducing of remote control systems, correlation of work procedures with safety requirements and with causes of accidents at work.

Modern numerical protections with advanced techniques and technologies ensure the efficient operation of the entire coordination and control protection system, fact that is an essential contribution for safe electric energy supply. [4]

Grouping the major risk factors on system work components, shows that the largest share of risk factors is given by risks generated by workers, with a rate of $39.1 \%$, followed by those generates by means of production / work equipment, with a percentage of $32.3 \%$.

Fig. 4 shows the distribution of major risk factors on operations and maintenance activities in power substations, divided by work system components.

From the graphic representation of the distribution of risk factors on work system components shown in Figure 3, fit appears that the most accidentogene situations, with potential risks of injury are those given by worker, with $36 \%$ and the means of production with $24 \%$.

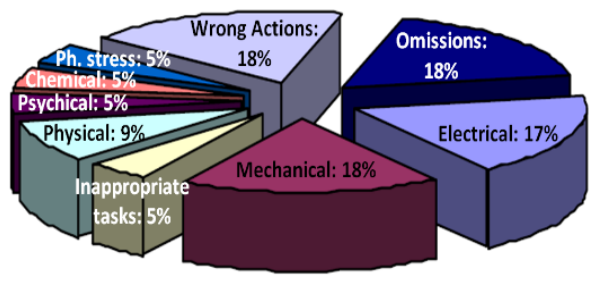

Fig. 5. Risk factors share identified in the electrical installations (overhead power lines)

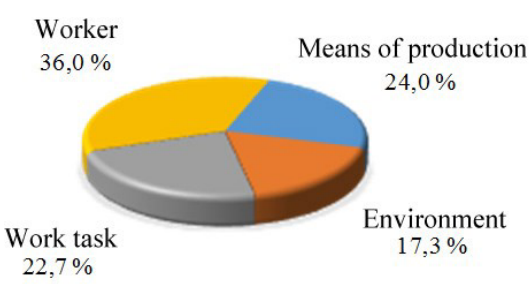

Fig. 6. The distribution of risk factors based on components of work components in the electrical installations (overhead power lines)

In case of the risks identified in the maintenance activity of the HV overhead lines (OHL) it is found that the largest share is held by the mechanical risk factors, risk factors 
generated by workers, with $18 \%$ and electrical risk factors with $17 \%$. Fig. 5 shows the share of the identified risk factors for maintenance activities of HV OHL [5].

Grouping the risk factors on work system components, it shows that the most dangerous situations in maintenance activities of the HV OHL, including potential risks of injury, are given by the worker, with $36 \%$ and means production / work equipment, with $24 \%$. The graphical representation of the distribution of risk factors on work system components is shown in Fig. 6 [5].

The weight of these risk factors is in decline due to upgrading programs and National Power System (NPS) interconnection with neighbouring power systems and due to expansion of activities carried out live Working (LW).

The maintenance activity on OHL live working is complex, the maximum foreseeable consequence for accidents at work, death and disability, requiring strict compliance of work technology for live working and of technical and organizational safety requirements in work area, use of work and safety equipment for live working, in accordance with the safety and technical requirements set by the applicable regulations, checked and tested regularly.

Taking into account the risks to which workers are exposed, complexity of the work, its specificity, training and education of workers must be continued and is necessary because during the execution of work, live working workers reaches deliberately the live parts of electrical installation or enter deliberately in live area [6].

The approach to the training an evaluation of Live Working personnel must have a scientifically base and must be a continuous and methodical concern for live working managers [7].

According to the top management of the national energy system, after more than 35 years in the LW, there has been no accident at high voltage.

This cannot be said in the case of live working in low-voltage installations where the risk factors generated by inappropriate technology, procedures or live working methods, risk factors generated by workers, by wrong actions and omissions hold the highest percentage.

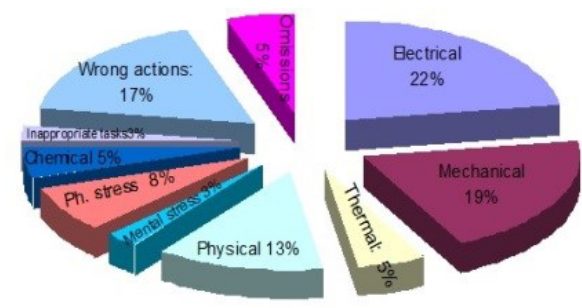

Fig. 7. The weight of the identified risk factors in electrical installations (UGL - 0.4,-110 kV)

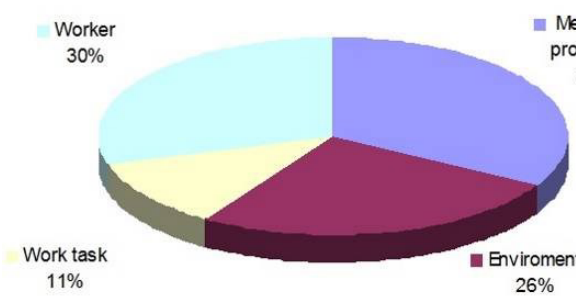

Fig. 8. The distribution of risk factors based on components of work components, in electrical installations (UGL - 0.4,-110 kV)

In the maintenance activities for underground power lines (UPL), the highest share of the identified risk factors it have the electrical risks, with $22 \%$ and mechanical risks, $19 \%$. Fig. 7 presents the share of identified risk factors in the maintenance activity of UPL.

Part of the work equipment, especially cables, were replaced, which led to the elimination of risks (risk of electric hazard, heat, fires, explosions, etc.), but many work equipment, especially in the low-voltage distribution transformers joints, is exceeded technical lifetime specified by the manufacturers [8].

From the representation of the distribution of risk factors on work system components, shown in Fig. 8 shows that the most dangerous situations, including potential risks of injury are those given by work equipment, with $33 \%$ and by worker with $30 \%$. 
Due to the fact that professional risk factors generated by the use of work equipment and by the workers are generally the basis of the technical or human hazards, resulting in the most cases invalidity or death, it is necessary to adopt some technical tools for managing the operation and maintenance activities of electrical installations.

The impact of these occupational hazards in companies require to continue to take technical and safety measures, modernization of work equipment, as well as continuous training of workers who undertake work in this sector

The research made by INCDPM over the years, led to the development of tools for the management of occupational hazards in the national economy in order to reduce the impact of occupational risks both in energy sector and related to operation and maintenance activities of work equipment in use.

For this purpose „Guidance on risk assessment and prevention of electrical risks” and "Risk management within professional equipment maintenance activities to prevent work accidents and occupational diseases - a prerequisite for increasing the competitiveness of employers on the market" developed in the research papers, are instruments that highlights the safety and health measures needed to be adopted in the national economy sectors, in order to reduce the impact of occupational risks and to manage more effectively the work carried out by the operating and maintenance workers in electrical installations and to ensure safe and healthy workplaces and to fulfil the objectives of occupational management.

\section{Conclusion}

Conducted studies over the years in electrical installations for use, distribution, transmission and production of electricity have allowed finding and drawing conclusions on the role, status and technical deficiencies of work equipment through the interaction of the four elements of work system.

In their activity, workers in electrical installations are subject to a number of factors risks from work equipment (e.g. electrical, mechanical, thermal, chemical risks), work environment (e. g. high / low temperature, air currents, humidity, weather, insufficient light - especially at night - dust, toxic gases, biological risk) and risk factors related to the workload that causes physical strain (e.g. the execution of manual work, forced postures, in narrow spaces, requiring professional gestures which requires strain of musculoskeletal and articular system when handling work equipment, various devices and tools) and mental strain (e.g. the performance of work in a short time, decisions in short time).

It is necessary the continuation of modernization of electrical equipment, the awareness of the importance and compliance of preventive maintenance programs, implementation of new technologies and procedures, correlation of technical and safety and health documents with the causes of accidents at work and occupational diseases, training, annual examination in terms of OHS for workers, all of these being technical and health and safety measures that can be adopted, resulting in reducing the impact of risks on operation and maintenance workers of electrical installations and to fulfil the objectives of occupational management.

\section{References}

1. A Antonov, G. Buica, C.Beiu, EEMJ, 13, (2014)

2. NSI - TEMPO program 2017

3. Dobra R., Buică G., Beiu C, Păsculescu D, WSEAS International Conference, Athena, Greece, 1, $58(2013)$ 
4. Păsculescu V, Şuvar M, Păsculescu D.,Transactions on Electronics and Communications, 56(70) Fasc. S1 (2011)

5. Buică G., Contributions of diagnostic methods of safty and health at work in electrical installations, Universitas, Petroşani, 70 (2010)

6. ASRO, SR EN 50110-1:2013 Operation of electrical installations. General requirements (2013)

7. MN Oltean, T Fagarasan, G Cotrigasanu, CIGRE Regional South-Est European Conferince, E111, 54-61 (2012)

8. INCDPM, Technical expertise on the assessment of working conditions of electrical installations for SC Electrica SA, between 1969-2001 required to establish group I work conditions (2009) 